\title{
INTERVENÇÕES PSICOLÓGICAS NUMA UNIDADE DE SAÚDE MENTAL FRENTE À PANDEMIA DO COVID-19: BREVE RELATO DE EXPERIÊNCIA ${ }^{1}$
}

\author{
PSYCHOLOGICAL INTERVENTIONS IN A MENTAL HEALTH UNIT IN \\ FRONT OF THE COVID-19 PANDEMIC: A BRIEF EXPERIENCE REPORT
}

\author{
Francine Zaltron Dias ${ }^{2}$ e Janaína Pereira Pretto Carlesso ${ }^{3}$
}

\section{RESUMO}

Este trabalho tem como finalidade apresentar de maneira breve as práticas e atividades desenvolvidas pelo acadêmico de Psicologia numa unidade de saúde mental no contexto da pandemia. A metodologia utilizada no trabalho baseia-se em método qualitativo de pesquisa, possuindo um caráter descritivo. Como resultado, é ressaltado que mesmo em um contexto mais restrito em decorrência de um vírus ainda desconhecido, é viável que as intervenções psicológicas que antes executadas ainda sejam fornecidas de forma ética e humanizada, tomando todos os cuidados necessários, porém excluindo a coordenação de grupos psicoterapêuticos em decorrência do distanciamento social. Sendo uma breve experiência, a mesma contribui de forma positiva para uma formação universitária mais humanizada como também um futuro profissionalismo com mais conhecimentos e técnicas frente a um cenário desconhecido.

Palavras-chave: Coronavírus; Psicologia; Hospital.

\section{ABSTRACT}

This work aims to briefly present the practices and activities developed by the Psychology student in a mental health unit in the context of the pandemic. The methodology used in the work is based on a qualitative research method, having a descriptive character. As a result, it is emphasized that even in a more restricted context due to a virus still unknown, it is feasible that the psychological interventions that were previously carried out are still provided in an ethical and humanized way, taking all necessary care, but excluding the coordination of groups. psychotherapeutic as a result of social distance. Being a brief experience, it contributes positively to a more humanized university education as well as a future professionalism with more knowledge and techniques in the face of an unknown scenario.

Keywords: Coronavirus; Psychology; Hospital.

\footnotetext{
${ }^{1}$ Trabalho resultante de prática de estágio obrigatório do curso de Psicologia (UFN).

${ }^{2}$ Acadêmica de graduação do Curso de Psicologia da Universidade Franciscana - UFN. E-mail: zaltrondias@gmail.com

${ }^{3}$ Orientadora. Doutora. Professora dos Cursos de Psicologia e do Mestrado em Ensino de Humanidades e Linguagens da Universidade Franciscana - UFN. E-mail: janapcarlesso@yahoo.com.br
} 


\section{INTRODUÇÃO}

O presente trabalho foi elaborado tendo como base uma breve experiência de estágio específico obrigatório no curso de Psicologia que teve durabilidade de um mês em decorrência do vírus, possuindo como campo de atuação a Unidade de Saúde Mental do Hospital São Francisco de Assis, localizado na cidade de Santa Maria, que visa o cuidado de pacientes com vulnerabilidades psíquicas em período de internação.

A pandemia do novo coronavírus (Covid-19) trouxe consequências significativas na vida de todos, atingindo diretamente a saúde pública de forma circunstancial em todo o mundo. A mesma trouxe consigo não só problemas físicos, como também afetou diretamente a saúde mental da comunidade internacional. Sendo um vírus desconhecido que está disseminando-se desde o mês de dezembro e que ainda não possui cura e nem vacina, o Covid-19 é uma doença causada pelo coronavírus, que denomina-se SARS-CoV-2, apresentando um espectro clínico que varia de infecções assintomáticas a quadros mais graves (MINISTÉRIO DA SAÚDE, 2020).

A área de atuação hospitalar faz com que o psicólogo considere o ser humano em sua globalidade e integridade, onde são realizadas diversas práticas que auxiliam no processo como o acolhimento, o atendimento individual psicoterapêutico, a coordenação de grupos, preparação para a alta e a realização de avaliações psicológicas. Assim sendo, o profissional se depara com diversas situações em diferentes setores nos quais sua prática pode ser efetiva, abrangendo não somente o paciente que está em processo de hospitalização, mas com um objetivo maior de auxiliar no processo saúde/doença, intentando proporcionar apoio psicológico através da compreensão, escuta e acolhimento (SILVA et al., 2017).

Contudo, levando em consideração um contexto de saúde mental com foco em internações, a Unidade de Saúde Mental necessitou passar por algumas mudanças relacionadas ao contexto interventivo psicológico, a fim de se adequar ao cenário atual e seguir produzindo efeitos positivos, como também ocasionar um olhar diferenciado frente às diversidades inclusas na vida dos pacientes através de uma visão psicológica fundamentada e com orientações através da supervisão.

Por conseguinte, este trabalho tem como finalidade apresentar de maneira breve as práticas e atividades desenvolvidas pelo acadêmico de Psicologia numa unidade de saúde mental em meio ao contexto da pandemia do novo coronavírus (Covid-19).

\section{METODOLOGIA}

A metodologia utilizada no trabalho tem como princípio um caráter descritivo, sendo então uma pesquisa qualitativa. A mesma busca o entendimento de fenômenos os quais são complexos e específicos de natureza social e cultural, por intermédio de descrições, interpretações e comparações, sem levar em considerações fatores numéricos, sejam eles matemáticos ou estatísticos (SILVA, 2004). 
As práticas que aqui serão relatadas são resultantes de um estágio específico obrigatório na grade do curso de Psicologia de uma instituição de ensino superior situada no interior do estado do Rio Grande do Sul. As atividades foram desenvolvidas durante todo o mês de julho de 2020, que terão continuidade no segundo semestre do mesmo ano, em uma Unidade de Saúde Mental pertencente ao hospital São Francisco de Assis, localizado na cidade de Santa Maria. Sendo assim, este relato traz experiências breves desenvolvidas em um campo de atuação da Psicologia diante a pandemia do novo Covid-19.

Visando melhor prosseguimento das práticas no âmbito de estágio, as mesmas serão acompanhadas pela professora responsável, onde acontecerão supervisões individuais a fim de trocar experiências, esclarecimento de dúvidas e orientações sobre novas formas de intervenções psicológicas em meio a mudanças na unidade.

O estágio contou com uma durabilidade de um mês, onde foram efetuadas 12 horas semanais, sendo 4 horas de prática, 2 horas de supervisão individual e 2 horas de estudo coletivo de casos. Tais práticas desenvolvidas como o acolhimento, atendimentos individuais, avaliações psicológicas e a busca ativa no contexto puderam ser executadas, excluindo então a coordenação de grupos por conta das exigências sanitárias.

Portanto, a análise será efetuada através de um relato de experiência ressaltando as vivências da estagiária na unidade e alguns impactos que a pandemia causou no contexto de intervenções psicológicas.

\section{RESULTADOS E DISCUSSÕES}

A Psicologia cada vez mais vem tomando espaço realizando práticas e ampliando seus saberes profissionais e suas técnicas em diversos âmbitos, dentre eles, o hospital. Anteriormente, tal local era designado em especial à medicina, porém, hoje em dia, o psicólogo desempenha um papel fundamental na busca da promoção e prevenção em saúde às pessoas inseridas nesse espaço. Essa prática foi possível graças à Resolução nº 014, decretada pelo Conselho Federal de Psicologia, a qual regulariza títulos de especialistas e inclui o psicólogo hospitalar (CFP, 2001). Tendo como um dos principais objetivos minimizar o sofrimento do paciente no momento em que está hospitalizado, ainda segundo o Conselho Federal de Psicologia (2001), o psicólogo hospitalar atua em níveis secundários e terciários de atenção à saúde, como na prestação de serviços não só aos pacientes, mas aos familiares e responsáveis do mesmo como também aos membros da equipe multidisciplinar e administrativa.

Tendo em vista apresentar de maneira breve as práticas e atividades desenvolvidas no hospital, direcionadas exclusivamente para um contexto de unidade de saúde mental, pode-se citar primeiramente o acolhimento. Sendo uma intervenção técnica e assistencial, tal prática visa acompanhar o paciente desde sua chegada à internação como também oportunizar uma breve avaliação do estado mental. Além disso, busca viabilizar um espaço onde o mesmo possa ser reconhecido e se reconhecer como participante ativo no processo de produção de sua própria saúde. Baseada em processos éticos, 
técnicos e humanitários, o acolhimento é uma forma sistemática de receber o paciente com receptividade, organização e atenção, se mostrando responsável e prestando um atendimento empático e resolutivo (COELHO, 2010).

Sobre a busca ativa no contexto, a qual é relacionada principalmente com conhecer a história de vida do paciente como um todo, e explorar também a existência de internações anteriores, Angerami (1994) traz que desconhecer a história vivencial da pessoa consiste em negligenciar o sentido próprio do trabalho do psicólogo hospitalar dentro desse contexto. Essa prática pode estar atribuída também ao local em si, onde se é necessário ter uma visão dinâmica de trabalho como forma de integração com todos os pacientes que estão na unidade.

Diante da pandemia do coronavírus, o atendimento individual ainda foi possível ser realizado na unidade, sempre contendo todos os cuidados de proteção individual e do outro. Foi possível então, o acompanhamento de alguns casos na sala da Psicologia. O mesmo é realizado através da psicoterapia breve ou focal, em processos de acompanhamento terapêutico. Dentro dessa prática hospitalar, vale salientar que a psicoeducação é extremamente importante nesse contexto, visando maior autonomia do paciente, não ensinando somente ele, mas também seus familiares sobre sua patologia e formas de tratamento, podendo ser desenvolvido um trabalho em conjunto sobre conscientização e prevenção em saúde (LEMES; NETO, 2017).

Outro método também muito utilizado neste contexto foi o de avaliação psicológica, que é entendida como um processo técnico-científico de coleta de dados no contexto hospitalar. Em específico, a mesma pode ser solicitada por membros da equipe, pela família ou até pelo próprio paciente, auxiliando também na tomada de decisões quanto a condutas médicas. Esse instrumento deve sempre estar aprimorando-se para que, a cada dia, possam ser desenvolvidas e criadas técnicas adequadas ao trabalho dinâmico, o qual é mais proposto em um âmbito hospitalar, facilitando assim o registro de dados psicológicos do paciente de forma clara, tanto para a equipe quanto para o próprio profissional da área da Psicologia (PESSÔA et al., 2015). Para a execução, foram utilizadas escalas e testes, assim como a entrevista de anamnese na busca de entender o processo de adoecer ou de hospitalização, através de interação pessoal, explorando contatos verbais e não verbais do paciente.

Os grupos psicoterapêuticos formados no ambiente hospitalar que são coordenados pelos estagiários de Psicologia possuem um importante papel de integração e empatia, podendo ser com pacientes acompanhados de seus familiares como também apenas com os pacientes da unidade. O grupo terapêutico tem o poder de potencializar as trocas dialógicas, o compartilhamento de experiências, e a melhoria de adaptação no modo de vida individual e coletivo (BENEVIDES et al., 2010). Portanto, o distanciamento social em decorrência da COVID-19 foi um empecilho, pois os grupos não puderam acontecer, mesmo sendo uma forma de intervenção muito rica no âmbito hospitalar.

Através de uma visão humanística que dá atenção especial aos pacientes, a Psicologia Hospitalar considera o ser humano em sua globalidade e integridade, única em suas condições pessoais, com 
seus direitos humanos preservados e bem definidos (ANGERAMI, 2004). Portanto, mesmo em um contexto mais restrito em decorrência de um vírus ainda desconhecido, é possível que as intervenções psicológicas sejam fornecidas de forma ética e humanizada, tomando todos os cuidados necessários.

Cabe salientar também, a importância do serviço de internação psiquiátrica, que é extremamente importante dentro do campo da saúde mental, seguir dando continuidade ao seu trabalho em tempos tão críticos como o de uma pandemia global, servindo de aparato às pessoas mais vulneráveis psiquicamente. O serviço de Psicologia no contexto do estágio realizado, objetiva garantir o bem-estar do indivíduo em crise que é internado na unidade, atuando em uma assistência que possibilita a contribuição para o paciente adaptar-se melhor ao processo de adoecimento e o desenvolvimento de formas mais adaptativas de enfrentamento para além da internação.

A pandemia do novo coronavírus trouxe consigo impactos econômicos, sociais, políticos e principalmente ligados a saúde mental da população, e que perpetuarão por um longo tempo. A situação atípica vivenicada mundial trouxe desafios que foram e estão sendo atravessados por profissionais da Psicologia, na busca de superar as dificuldades com um mesmo foco, que é pensar na melhor qualidade de vida para cada sujeito. Mesmo que em um curto período de tempo, pode-se observar a importância de serviços como esse, que reformularam e ressignificaram práticas visando um cuidado maior e assim reinventando-se.

\section{CONCLUSÃO}

Este trabalho apresentou breves experiências de uma acadêmica de Psicologia em um estágio específico obrigatório com foco em intervenções psicológicas desenvolvidas em uma unidade de saúde mental frente a pandemia do novo coronavírus. As práticas terão continuidade no mesmo local, ao longo do segundo semestre de 2020.

No que se refere às práticas realizadas, vale ressaltar que a maioria delas puderam ser desenvolvidas normalmente, apenas incluindo a tomada de cuidados sanitários e exigentes visando o cuidado próprio e o cuidado com o outro em relação ao contágio, como também o distanciamento social. Em decorrência do último, os grupos psicoterapêuticos não puderam ser efetuados, os quais agregariam de forma positiva na internação dos pacientes.

Contudo, essa privação não prejudicou as demais práticas exercidas, pois foram desenvolvidas de forma ética, sigilosa, profissional e empática, visando sempre o bem-estar físico e psíquico do paciente que se encontrava vulnerável na unidade. Sendo assim, a estagiária de Psicologia é uma peça ímpar que fez e irá fazer a diferença na vida destes pacientes, com um olhar mais humano, auxiliando em questões subjetivas e enxergando-os como um todo, para além de uma patologia. Logo, é uma breve experiência a qual contribui de forma positiva para o desenvolvimento de uma profissional com mais conhecimentos e técnicas direcionadas a contextos que 
por si só já são adoecedores frente a um cenário desconhecido, como também na contribuição de uma melhor formação universitária mais humanizada.

Por fim, cabe ressaltar que este trabalho se mostra como uma análise parcial das práticas que foram realizadas com durabilidade de um mês por conta do cenário atual, não havendo a intenção de esgotar o assunto, considerando que o âmbito de unidades de internação em saúde mental ainda precisa de um enfoque maior em referência a estudos e pesquisas na área.

\section{REFERÊNCIAS}

ANGERAMI-CAMON, V. A. E a Psicologia entrou no hospital. São Paulo: Pioneira. 2004.

ANGERAMI-CAMON, V. A. Psicologia hospitalar: teoria e prática. São Paulo: Pioneira. 1994.

BENEVIDES, D. S. et al. Cuidado em Saúde Mental por meio de grupos terapêuticos de um hospital-dia: perspectivas dos trabalhadores de saúde. Interface (Botucatu), Botucatu, v. 14, n. 32, p. 127-138, março, 2010. Disponível em: https://bit.ly/3qWCRAl. Acesso em: 02 ago. 2020.

BRASIL. Ministério da Saúde. Secretaria de Políticas da Saúde. Coronavírus (Covid-19). Brasília, DF, 2020.

COELHO, F. V. Acolhimento em Saúde Mental na Unidade Básica: uma revisão teórica. Belo Horizonte: Universidade Federal de Minas Gerais, 2010. Disponível em: https://bit.ly/3qZPpGZ. Acesso em: 02 ago. 2020.

CONSELHO FEDERAL DE PSICOLOGIA. Resolução nº 02/01 de 22 de março de 2001. Altera e regulamenta a Resolução CFP no 014/00 que institui o título profissional de especialista em psicologia e o respectivo registro nos Conselhos Regionais. Disponível em: https://bit.ly/3aharLu. Acesso em: 02 ago. 2020.

LEMES, C. B.; NETO, J. N. Aplicações da psicoeducação no contexto da saúde. Temas em Psicologia, Ribeirão Preto, v. 25, n. 1, p. 17-28, março, 2017. Disponível em: https://bit.ly/37qBOAZ. Acesso em: 01 ago. 2020.

PESSÔA, K. P. et al. A avaliaçã psicológica no contexto hospitalar. Mostra de Iniciação Científica do CESUCA, n. 9, p. 370-377, dezembro, 2015. ISSN 2317-5915. Disponível em: https://bit.ly/3gTZFvU. Acesso em: 02 ago. 2020. 
SILVA, C. R. O. Metodologia e organização do projeto de pesquisa: guia prático. Fortaleza: Editora da UFC, 2004.

SILVA, C. S. R; ALMEIDA, M. L; BRITO, S.S; MOSCON, D. C. B. Os desafios que os psicólogos hospitalares encontram ao longo de sua atuação. Rev Científica Unifacs, Salvador, v. 16, 2017. 
